\title{
Large-scale production of cellulose-binding domains. Adsorption studies using CBD-FITC conjugates
}

\author{
Ricardo Pinto, Joana Carvalho, Manuel Mota and Miguel Gama* \\ Centro de Engenharia Biológica, Universidade do Minho, Campus de Gualtar, 4710-057, Braga, Portugal; \\ *Author for correspondence (e-mail: fmgama@deb.uminho.pt; phone: +351-25-3604400; fax: + 351-25- \\ 3678986)
}

Received 23 June 2005; accepted in revised form 11 February 2006

Key words: Adsorption, Cellulose-binding domains, FITC, Proteolysis

\begin{abstract}
A method for the gram-scale production of cellulose-binding domains (CBD) through the proteolytic digestion of a commercial enzymatic preparation (Celluclast) was developed. The CBD obtained, isolated from Trichoderma reesei cellobiohydrolase I, is highly pure and heavily glycosylated. The purified peptide has a molecular weight of $8.43 \mathrm{kDa}$, comprising the binding module, a part of the linker, and about $30 \%$ glycosidic moiety. Its properties may thus be different from recombinant ones expressed in bacteria. CBDfluorescein isothiocyanate conjugates were used to study the CBD-cellulose interaction. The presence of fluorescent peptides adsorbed on crystalline and amorphous cellulose fibers suggests that amorphous regions have a higher concentration of binding sites. The adsorption is reversible, but desorption is a very slow process.
\end{abstract}

Abbreviations: CBHI - Cellobiohydrolase I; CBHII - Cellobiohydrolase II; CBD - Cellulose-binding domain; $\mathrm{CBD}_{\mathrm{CBHI}}, C B D_{C B H I I}$ - Cellulose-binding domain of cellobiohydrolase I and II, respectively; FITC - Fluorescein isothiocyanate

\section{Introduction}

Cellulose is a polymer formed by chains of thousands of glucose molecules linked by $\beta$-1,4-glycosidic bonds. Hydrogen bonds firmly hold these chains together to form microfibrils, which in turn are packed together to form fibers with a predominantly crystalline character. Microorganisms use a consortium of enzymes to degrade this insoluble material efficiently.

One of these microorganisms is Trichoderma reesei, a fungus that primarily produces two exoglucanases (cellobiohydrolase I and II)(80-90\%) as well as several endoglucanases (I, II and V)
(Srisodsuk 1994). These two types of enzymes act either at the loose ends of the microfibrils (exoglucanases) or randomly from within the macromolecular chain (endoglucanases). One common feature of many of these enzymes is their modular assembly, which is formed by a catalytic domain, a cellulose-binding domain (CBD) and a highly glycosylated linker (Hui et al. 2001).

The CBD plays a major role in determining the function of a specific enzyme by endowing the protein with cellulose affinity (Srisodsuk et al. 1993). CBDs have highly conserved sequences, namely a three aromatic residue strip that appears to be implicated in the binding process (Mattinen 
et al. 1997). Two features differentiates the CBDs of cellobiohydrolases I and II: (1) one of the CBHII residues in the hydrophobic strip is a tryptophan instead of tyrosine; (2) the number of disulfide bridges is different (three in CBHII, only two in CBHI). These differences appear to have a major impact in the adsorption behavior: $\mathrm{CBD}_{\mathrm{CBHII}}$ irreversibly binds bacterial microcrystalline cellulose (BMCC), whereas $\mathrm{CBD}_{\mathrm{CBHI}}$ adsorption is reversible (Carrard and Linder 1999; Linder et al. 1999).

Xiao et al. (2001) showed that the CBD from endoglucanase III has the ability to disrupt the crystalline structure of cellulose fibers. A similar result was observed with a CBD from Penicillium janthinellum during a treatment of cotton fibers (Gao et al. 2001). Yet another interesting investigation (Carrard et al. 2000) revealed that different CBDs adsorb to different sites on the surface of crystalline cellulose. These results strongly suggest that CBDs may be functionally quite sophisticated and consequently more than just a tool for enzyme absorption.

Limited proteolysis of cellulases has been used by several authors to isolate the catalytic domain (Tilbeurgh et al. 1986; Lemos et al. 2000; Harrison et al. 2002) but not to effect the large-scale production of binding modules, as described in the investigation reported here. In order to study the interaction of CBDs with cellulose, the CBDs obtained were used to analyze the adsorption and distribution of FITC-labeled CBDs on different cellulose materials.

\section{Materials and methods}

\section{Chemicals}

FITC was obtained from Sigma (St. Louis, Mo.). The cellulose samples were obtained from Fluka (Avicel PH-101) and Sigma-Aldrich (Whatman CF11). All chemicals were of the highest purity available.

\section{CBD production}

The commercial enzymatic preparation Celluclast 1.51 (Novozymes A/S, Denmark), produced by the fungus Trichoderma reesei, was firstly diluted 1:4 with acetate buffer ( $\mathrm{pH} 5.0,25 \mathrm{mM})$ and then dia-filtered through a $30-\mathrm{kDa}$ ultra-filtration membrane using a Pellicon 2 TFF System (Millipore, Bedford, Mass.). The papain activation was carried out by mixing a diluted solution $(1: 1000, \mathrm{v} / \mathrm{v})$ of $\beta$-mercaptoethanol with papain (1:10) for $15 \mathrm{~min}$. After $4 \mathrm{~h}$ of proteolysis at room temperature, the solution was filtered through a $10-\mathrm{kDa}$ membrane and the permeate recovered. Ammonium sulphate was then added $(700 \mathrm{~g} / \mathrm{l})$ to the permeate solution in order to precipitate the peptides, which were recovered by centrifugation at 12,225 RCF (relative centrifugal acceleration) for $40 \mathrm{~min}$ (Sigma $4 \mathrm{K10}$; B. Braun). This concentrated solution was finally dialyzed against phosphate buffer (pH 7.5, $20 \mathrm{mM}$ ), using a 1-kDa cutoff membrane. Deglycosylated CBD were prepared as described elsewhere (Edge et al. 1981).Treatment with trifluoromethanesulfonic acid (TFMS) was carried out for $30 \mathrm{~min}$; longer periods led to fragmentation of the protein, while shorter periods were insufficient for complete sugar removal (as monitored by sugar and protein quantification of the dialyzed material).

\section{Ion exchange chromatography (IEC)}

The peptides were further purified using a column packed with DEAE Sepharose Fast-Flow gel (Amersham Pharmacia Biotech AB, Sweden), using phosphate buffer ( $\mathrm{pH} 7.5,20 \mathrm{mM}$ ) as eluent and a flow rate of $3 \mathrm{ml} / \mathrm{min}$. The first peak (nonadsorbed protein) was recovered and lyophilized.

\section{$N$-terminal peptide sequencing}

Purified CBD were sequenced on an Applied Biosystems Procise 491 HT according to manufacturer's specifications (Applied Biosystems, Foster City, Calif.).

\section{Capillary electrophoresis}

A BioFocus 2000 Capillary Electrophoresis System (Bio-Rad, Hercules, Calif.) was used. All of the solutions used were purchased from Bio-Rad (CE-SDS Protein kit). An uncoated fused-silica (Bio-Rad) capillary with an internal diameter of 
$50 \mu \mathrm{m}$ and a length of $24 \mathrm{~cm}$ was used. The electrophoresis run conditions were as follows: capillary temperature, $20^{\circ} \mathrm{C}$; CE-SDS Protein Run Buffer; $15 \mathrm{kV}$ constant run voltage; on-line detection at $220 \mathrm{~nm}$; electrophoretic injection by application of $15 \mathrm{kV}$ for $10 \mathrm{~s}$. Calibration was performed with three proteins (Sigma-Aldrich) of known molecular sizes: bovine serum albumin (BSA; $66 \mathrm{kDa})$, pepsin $(35 \mathrm{kDa})$ and lysozyme $(14.5 \mathrm{kDa})$.

\section{Sugar analysis}

The monosaccharides in the CBD glycosidic fraction were released by Saeman hydrolysis (Selvendran et al. 1979) and analyzed as their alditol acetates by gas chromatography (GC) (Blakeney et al. 1983; Harris et al. 1988) using a Chrompack CP9001 equipped with a Flame Ionization Detector and a Varian CP-Sil 88 column. Total sugars were also measured using the phenol-sulfuric method (Dubois et al. 1956), with mannose as the standard.

\section{Matrix-assisted laser desorption/ionization-time of flight mass spectrometry (MALDI-TOF)}

The measurements were made on a VoyagerDE STR (Applied Biosystems). The sample was diluted on the matrix reagent, sinapinic acid. Calibration was performed using the Pepmix 3 (LaserBio Labs, France) peptide mix.

\section{$C B D$ affinity and binding reversibility}

Suspensions of Whatman CF11 fibers, with a concentration of $10 \mathrm{mg} / \mathrm{ml}$ in sodium acetate buffer (50 mM, pH 5.0), were incubated for $16 \mathrm{~h}$ at $5{ }^{\circ} \mathrm{C}$, with magnetic agitation, in the presence of different $\mathrm{CBD}$ concentrations $\left(\mathrm{CBD}_{\text {Initial }}\right)$. The fibers were then centrifuged at $4000 \mathrm{rpm}$ for $10 \mathrm{~min}$, and the CBD concentration in the supernatant $\left(\mathrm{CBD}_{\text {Unbound }}\right)$ was measured in a Jasco FP6200 spectrofluorimeter (Santa Ana, Calif.) operated at emission and excitation wavelengths of 341 and $275 \mathrm{~nm}$, respectively. The apparatus was calibrated using CBD solutions in which the concentrations had been determined using the BCA
Protein Assay (Pierce Co.). The bound CBD was calculated using the following equation:

$$
\begin{gathered}
\mathrm{CBD}_{\text {Bound }}=\frac{\left[\mathrm{CBD}_{\text {Initial }}\right]-\left[\mathrm{CBD}_{\text {Unbound }}\right]}{m_{\mathrm{CF} 11}} \times V_{R} \\
\left(\mu \mathrm{mol}_{\mathrm{CBD}} / \mathrm{g}_{\mathrm{CF} 11}\right)
\end{gathered}
$$

where $V_{R}$ corresponds to the volume of the buffer used, $\left[\mathrm{CBD}_{x}\right]$ to the molar concentration of CBD and $m_{\mathrm{CF} 11}$ to the mass of the fibers.

\section{Fluorescence spectroscopy}

A FP-6200 spectrofluorimeter (Jasco) was used. The band width of excitation and emission was $5 \mathrm{~nm}$, and the scan speed was $1000 \mathrm{~nm} / \mathrm{min}$. A constant excitation at $275 \mathrm{~nm}$ was used.

\section{Amorphous cellulose preparation}

Amorphous cellulose was prepared by treating Whatman CF11 fibers with phosphoric acid. Briefly, $0.17 \mathrm{~g}$ of Whatman CF11 was slowly mixed with $10 \mathrm{ml}$ of cold $\left(4^{\circ} \mathrm{C}\right)$ phosphoric acid $(85 \%)$ and left in contact for $5 \mathrm{~min}$. Then, $600 \mathrm{ml}$ of cold water was added and the suspension filtered through a test sieve (mesh width: $71 \mu \mathrm{m}$ according to DIN 4188). Finally, the fibers were extensively washed, first in tap water and afterwards with distilled water. The obtained material was lyophilized and stored.

\section{CBD-FITC conjugation and adsorption}

FITC is a fluorescent probe widely used to attach a fluorescent label to proteins by a reaction with amine groups. CBDs were labeled by standard procedures. Briefly, $20 \mu \mathrm{g}$ of FITC was added per milligram of CBD (in a concentration of $2 \mathrm{mg}$ protein $/ \mathrm{ml}$ in $0.1 M$ HEPES buffer, $\mathrm{pH} 9.0$ ). This solution was incubated overnight in the dark, at room temperature, with magnetic stirring. To separate unbound FITC from FITC-CBD, the mixture was filtered through a BIO-GEL P-4 (Bio$\mathrm{Rad}$ ) column previously equilibrated with $50 \mathrm{mM}$ sodium acetate buffer ( $\mathrm{pH}$ 5.0). Fractions containing significant amounts of FITC-CBD were pooled. Fluorescence at an excitation/emission of 
$275 / 310 \mathrm{~nm}$ and $495 / 525 \mathrm{~nm}$ was measured to determine CBD concentration and FITC fluorescence, respectively.

Adsorption assays were carried out at $4{ }^{\circ} \mathrm{C}$. Different concentrations FITC-labeled CBD solutions were mixed in the dark with cellulose fibers $(20 \mathrm{~g} / \mathrm{l})$ in $50 \mathrm{~m} M$ sodium acetate buffer to a final volume of $4 \mathrm{ml}$. The suspension was continuously stirred. After a 2-h reaction, cellulose fibers with bound CBDs were removed by centrifugation at $3219 \mathrm{RCF}$ for $10 \mathrm{~min}$ (Heraeus Megafuge 1.0R). The difference between the initial amount of CBD and that of the supernatant enabled the amount of bound CBD to be calculated based on the intensity of the fluorescence emission at $310 \mathrm{~nm}$ with an excitation of $275 \mathrm{~nm}$.

Fluorescence microscopy observations were performed in a Zeiss AxiosKop microscope. The images were acquired with a Zeiss AxioCam HRc camera and analyzed with AxioVIsion 3.1 software.

\section{Results and discussion}

\section{Large-scale production of $C B D$}

The main enzymes produced by $T$. reesei have an average size of approximately $50 \mathrm{kDa}$ (Swiss-Prot database; Gasteiger et al. 2003). The capillary electrophoresis analysis (Figure 1) of the Celluclast proteins provided an estimated molecular weight of approximately $90 \mathrm{kDa}$ based on the calibration performed with protein standards. This overestimation may be due to the presence of the glycosidic moiety, which may affect the migration time of the enzymes by changing the overall protein charge, as shown by Leach et al. (1980) and Legaz et al. (1998). These authors demonstrated that the glycosidic moiety may increase the negative charge of an anionic protein since the hydro$\mathrm{xyl}$ groups in the sugar structure behave as weak acids. Consequently, the migration of glycosylated proteins during capillary electrophoresis will be affected by the presence of the glycosidic moiety, therefore this technique herein used to monitor, qualitatively, the relative size of the peptides obtained by papain proteolysis.

We subjected Celluclast to proteolysis using several dilutions of the activated papain. As can be seen in the electropherogram shown in Figure 2, heavier loads of papain resulted in a rather dramatic reduction in the main peak corresponding to higher molecular-weight proteins; this reduction was concomitant with an increase in the peaks corresponding to lower molecular-weight material. Based on these results, we selected the relative amounts of papain/cellulase to be used for the production of CBD ( $1 \mathrm{~g}$ of activated papain for each $1200 \mathrm{~g}$ of protein in the $30-\mathrm{kDa}$ ultra-filtered Celluclast); at higher concentrations of papain than that chosen, hydrolysis is too extensive. The production of a mixture of low-molecular-weight fragments was avoided by using the selected concentration of papain (see following section). The electropherogram obtained with the purified CBD

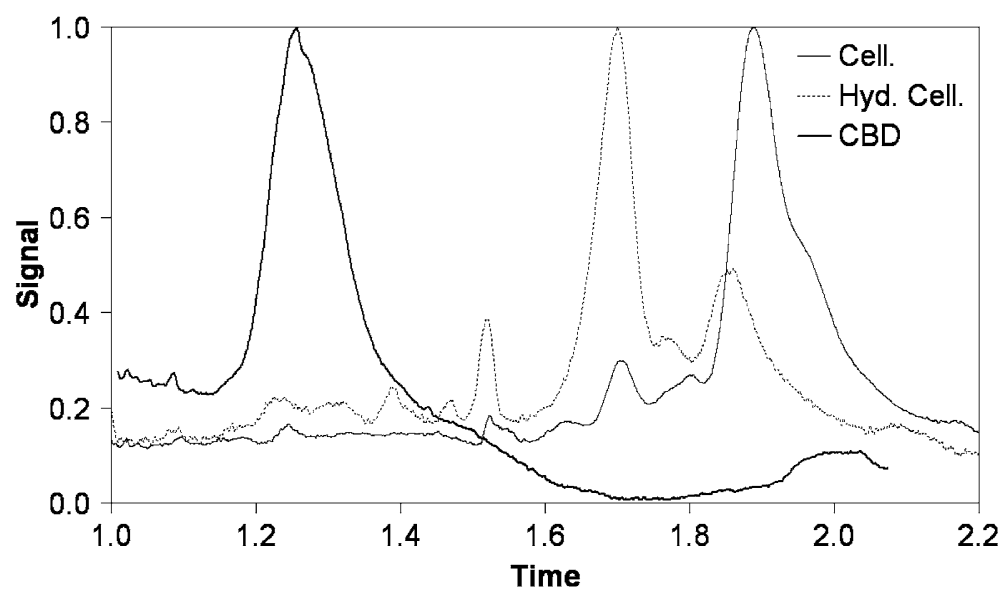

Figure 1. Electropherogram of Celluclast (Cell.), hydrolyzed Celluclast ( Hyd. Cell.) and cellulose-binding domains (CBD). Both time and signal are normalized. 


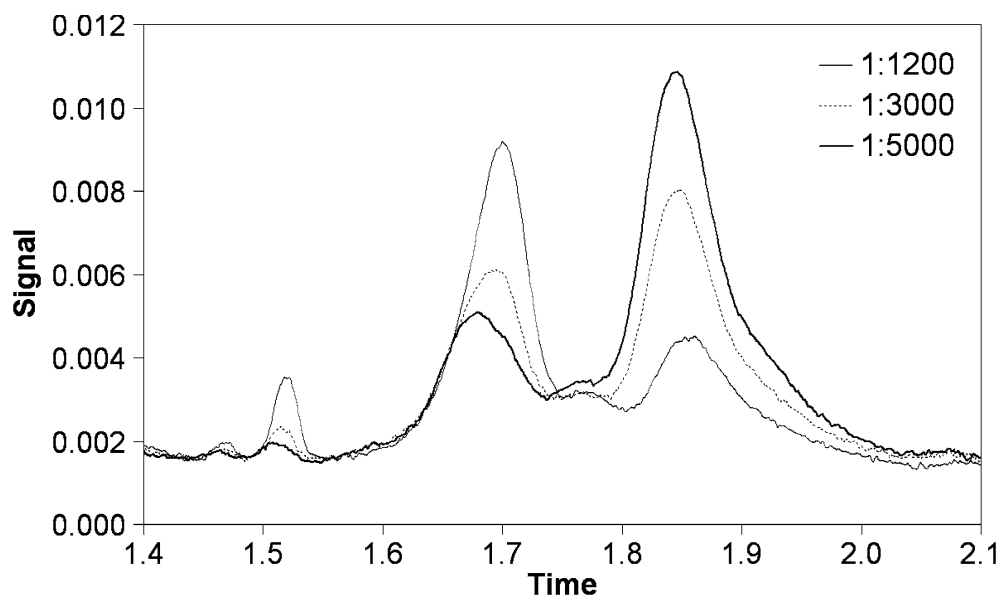

Figure 2. Electropherogram of Celluclast hydrolyzed with different amounts of papain based on protein weight (the dilution factor of the commercial enzyme is shown). Time is normalized.

(Figure 1) revealed a low-molecular-weight peptide, with no apparent contamination from higher molecular-weight material. Again, the migration time of this peptide was higher than the expected for a CBD, corresponding to a mass of about 20 to $30-\mathrm{kDa}$. This high apparent molecular weight may be explained by the glycosidic moiety present on the linker (rich in threonin and serine residues), since CBD has no potential sites for glycosylation (Harrison et al. 1998; Hui et al. 2001). The peptide obtained comprised $30 \%(\mathrm{w} / \mathrm{w})$ carbohydrates, as determined by the total sugar analysis, with a monosaccharide composition of $85 \%$ mannose, $12 \%$ galactose and minor amounts of other sugars, as determined by GC.

The MALDI-TOF analysis of the purified CBD is shown in Figure 3. The sample is highly microheterogeneous in size, with a main peak detected at $8.43 \mathrm{kDa}$. The several satellite peaks have an almost constant difference from one another of 162 $( \pm 1)$ mass units $(8106,8267,8430,8591,8755$, $8917,9080 \mathrm{Da})$ that presumably arises from differential glycosylation (Letourneur et al. 2001; Hui et al. 2001). A lower molecular-weight group of peaks, at $4.21 \mathrm{kDa}$, corresponds to the same peptide, with a charge of $2+$. A series of peaks with half the mass of the ones listed above were detected (4053, 4134, 4215, 4296, 4379, 4459, 4539, $4622 \mathrm{Da})$, with a difference between peaks of 81 $( \pm 1)$ mass units. This pattern, in our view, can be attributed only to a protein having undergone heterogeneous glycosylation. The concentration of fragments with a very narrow size distribution (from 8 to $9 \mathrm{kDa}$ ) indicates that proteolysis was quite mild, otherwise a scattered size distribution of low-molecular-weight peptides would be observed even though papain is a proteolytic enzyme with a broad specificity (Price and Johnson 1990). The MALDI spectra furthermore suggest (as demonstrated in the following section on sequential analysis) that the peptide is highly pure, since no high-molecular-weight peaks were detected.

Proteolysis of Celluclast allowed the production of over $2 \mathrm{~g}$ of $\mathrm{CBD}$, starting from $50 \mathrm{~g}$ of protein. This material was further purified by IEC which revealed a main peak of non-adsorbed material (uncharged, corresponding to CBDs) and a second peak, eluted with a $\mathrm{NaCl}$ gradient, corresponding to charged material (cellulases and catalytic domains with acidic $\mathrm{pI}$ ). To further characterize these purified peptides, the fluorescence spectra of the CBD samples were analyzed, before and after ion exchange chromatography. Tyrosine and tryptophan residues have a maximum emission at 305 and $340 \mathrm{~nm}$, respectively. According to the spectra shown in Figure 4, the chromatography step removed a substantial part of the tryptophan residues present in the solution. The CDB from CBHI is, among the enzymes produced by $T$. reesei, the only one missing tryptophan (Kraulis et al. 1989; Gasteiger et al. 2003). Consequently, it appears that the CBD obtained are mostly from CBHI, as expected, since this is the most abundant enzyme secreted by $T$. reesei. N-terminal sequence analysis confirmed this hypothesis. The sequence obtained, GNPPG, is present only in CBHI, between the 


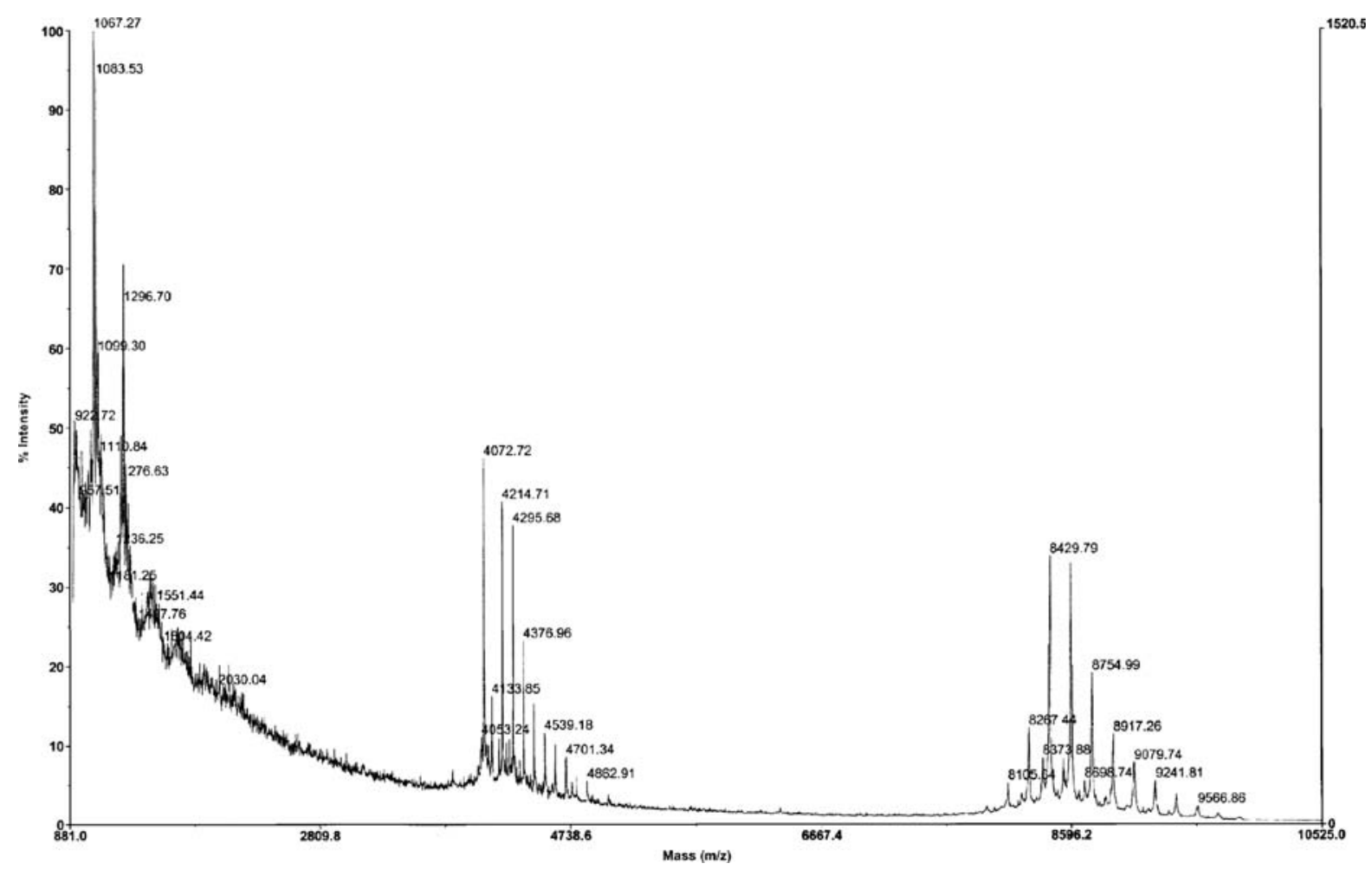

Figure 3. MALDI-TOF analysis of the purified CBD peptides.

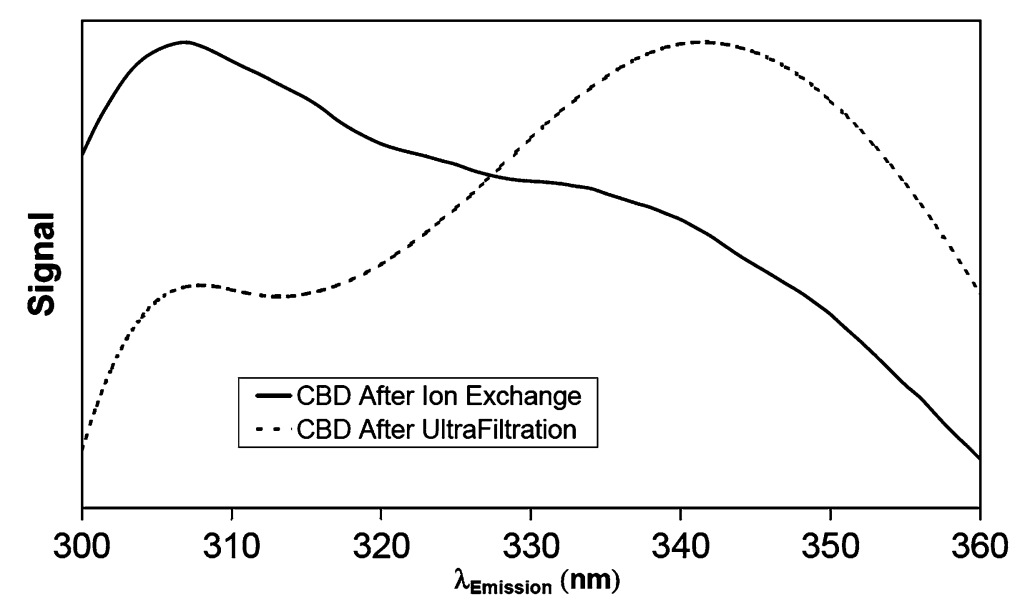

Figure 4. Fluorescence spectrums of CBD following ultra-filtration and subsequent ion exchange purification. Signals are normalized to the highest value obtained on each measurement.

catalytic domain and the linker (Gasteiger et al. 2003). Since the isolated peptides are produced by papain cleavage, the presence of $\mathrm{N}$-terminal blocked peptides in the mixture is rather unlikely. Thus, the result in Figure 5 demonstrates that the CBD purified by IEC are rather pure, since only one amino acid is released in each step of the $\mathrm{N}$-terminal sequence analysis. Taken together with evidence from the MALDI analysis, it is possible to conclude that highly pure CBD have been obtained and that papain (in the conditions of the assay) cleaves $\mathrm{CBHI}$ in a single position of the peptide 


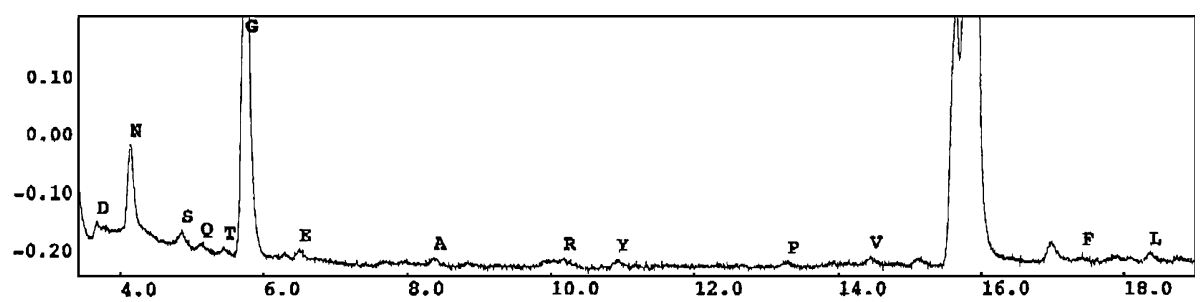

Figure 5. Chromatogram of the first amino acid detected on the N-terminal peptide sequencing of the purified CBD. This chromatogram reveals that the isolated $\mathrm{CBD}$ is rather pure.

sequence, a somewhat surprising result. This suggests a protection of the linker against proteolysis, due to glycosylation, and that there is only one site exposed to the protease. The theoretical molecular weight of the protein exhibiting the $\mathrm{N}$ terminal GNPPG is $6.22 \mathrm{kDa}$ (Gasteiger et al. 2003 , which is indicative of a $8.43-\mathrm{kDa}$ protein(determined by MALDI) comprising about $30 \%$ sugars. Several authors (for example, Harrison et al. 1998; Hui et al. 2001) have reported strains of $T$. reesei which produce peptide sequences different from that reported in the SwissProt database (http://www.expasy.ch/cgi-bin/niceprot.pl?P62694), where the arginine in position 442 is substituted by two prolines $\left({ }^{431}\right.$ NPSGGNPPGG NPPGTTTTRR ${ }^{450}$ ). In this case, a 5.84-kDa protein exhibiting the N-terminal sequence GNPPG would be obtained by proteolysis. MALDI-TOF analysis of the deglycosylated CBD (Figure 6) revealed a protein (the main one in the mixture) that exactly matches this value, $5.84 \mathrm{kDa}$.

The removal of the tryptophan-containing peptides by IEC also led to an increase in the cellulose affinity of the remaining material, as revealed by the analysis of the Langmuir adsorption isotherm (Kim et al. 2001):

$$
\mathrm{CBD}_{\text {Bound }}=\frac{\mathrm{CBD}_{\mathrm{Max}} \cdot K_{a} \cdot[\mathrm{CBD}]_{\text {Free }}}{1+K_{a} \cdot[\mathrm{CBD}]_{\text {Free }}}
$$

where $\mathrm{CBD}_{\text {Bound }}$ is the molar amount of protein adsorbed, per unit weight of cellulose, $[\mathrm{CBD}]_{\text {Free }}$ is the molar protein concentration in the liquid phase at the adsorption equilibrium, $\mathrm{CBD}_{\mathrm{Max}}$ and $K_{a}$ are the maximum molar amount of protein adsorbed, per unit weight of cellulose, and the adsorption

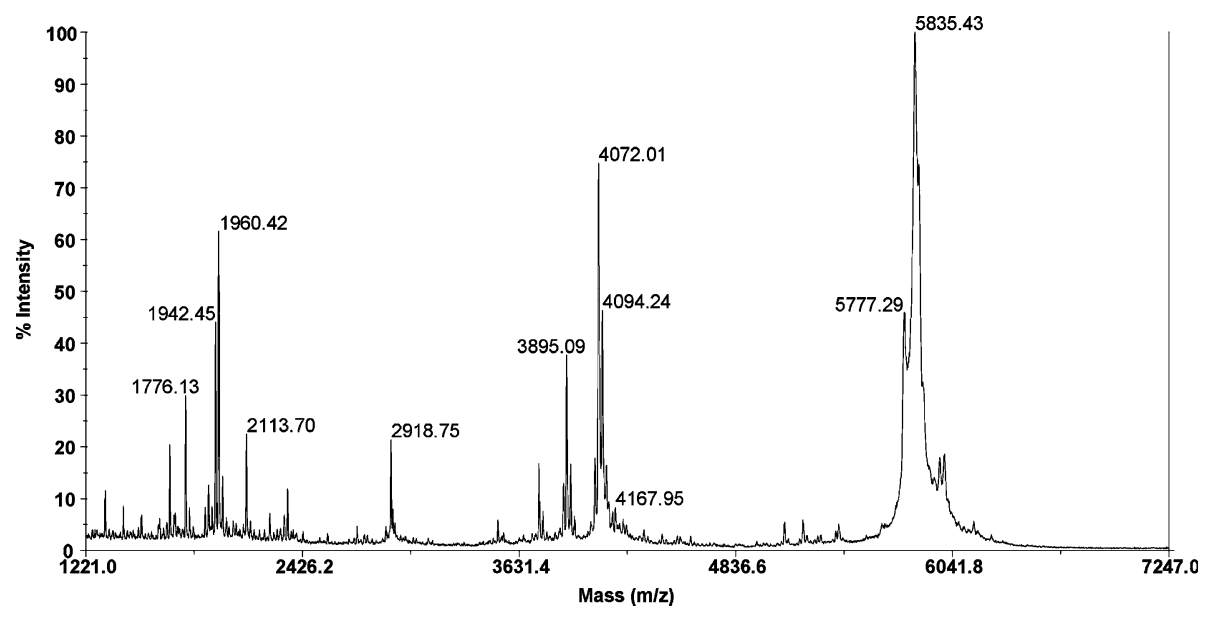

Figure 6. MALDI-TOF analysis of the deglycosylated CBD peptides. The heterogeneous peak observed in Figure 3 (8.43 kDa) is replaced by a main peak at $5.84 \mathrm{kDa}$. The complete removal of the glycosidic fraction with TFMS leads to some proteolysis, with the appearance of several peaks (1700-4000 Da) not observed prior to TFMS treatment (nor when the treatment was performed under milder conditions). 
equilibrium constant, respectively. Non-linear regression analysis was used to calculate the parameters of the adsorption isotherm (Figure 7): $\mathrm{CBD}_{\mathrm{Max}}$ and $K_{a}$ are equal to $4.62 \mu \mathrm{mol} / \mathrm{g}$ and $0.192 \mathrm{1} / \mu \mathrm{mol}$ as compared to $3.13 \mu \mathrm{mol} / \mathrm{g}$ and $0.1331 / \mu \mathrm{mol}$, respectively, for CBD before and after IEC (Pinto et al. 2004). Values for the partition coefficient (initial slope of the adsorption isotherm) increased from $0.35 \mathrm{l} / \mathrm{g}$ (previous data) to $0.89 \mathrm{l} / \mathrm{g}$. It would appear that the main result of chromatographic step was to remove peptides with a low affinity for cellulose.

Highly purified cellulose-binding modules may be obtained using DNA technology (Creagh et al. 1996; Bothwell et al. 1997; Linder et al. 1999). The purification of CBD through the proteolysis of cellulases, as described in this work, provides large amounts of peptides in a rather rapid procedure. This method may be useful in a number of applied and analytical studies. The CBD obtained includes a part of the linker and is heavily glycosylated, as expressed by fungi. In this regard, these peptides are different from those available by recombinant DNA technology and, furthermore, in our view, its properties should be analyzed and compared to those of nonglycosylated CBDs. This material may also be used for structural studies of oligosaccharides from the $\mathrm{CBHI}$ linker.
Studies on the adsorption of CBD-FITC conjugates

Cellulose is the main component in many commercial products, from textile to paper and filtration membranes. CBD can mediate the targeting of functional molecules to cellulose-containing materials (Levy et al. 2002), thereby endowning new properties and functions to those materials. On the other hand, as it has been suggested by some authors (Gao et al. 2001; Xiao et al. 2001), CBD are capable of non-hydrolytic disruption activity and surface modification of cellulose fibers. Previous studies demonstrated that CBD may have a beneficial effect on pulp properties (Suurnakki et al. 2000) and can be useful in paper recycling (Pala et al. 2001). Consequently, CBD technology is a valuable tool in the development of modified materials with improved properties.

Having this in mind, we attempted to evaluate CBD distribution in cellulose surfaces. This was achieved by attaching a fluorescent probe (FITC) to the CBD and then observing the fibers treated with the labeled CBD microscopically using a filter to select fluorescence emission. A control assay was carried out using free FITC (not linked to CBD) in order to detect nonspecific adsorption to cellulose. The presence of free FITC molecules mixed with CBD-FITC is unlikely because the

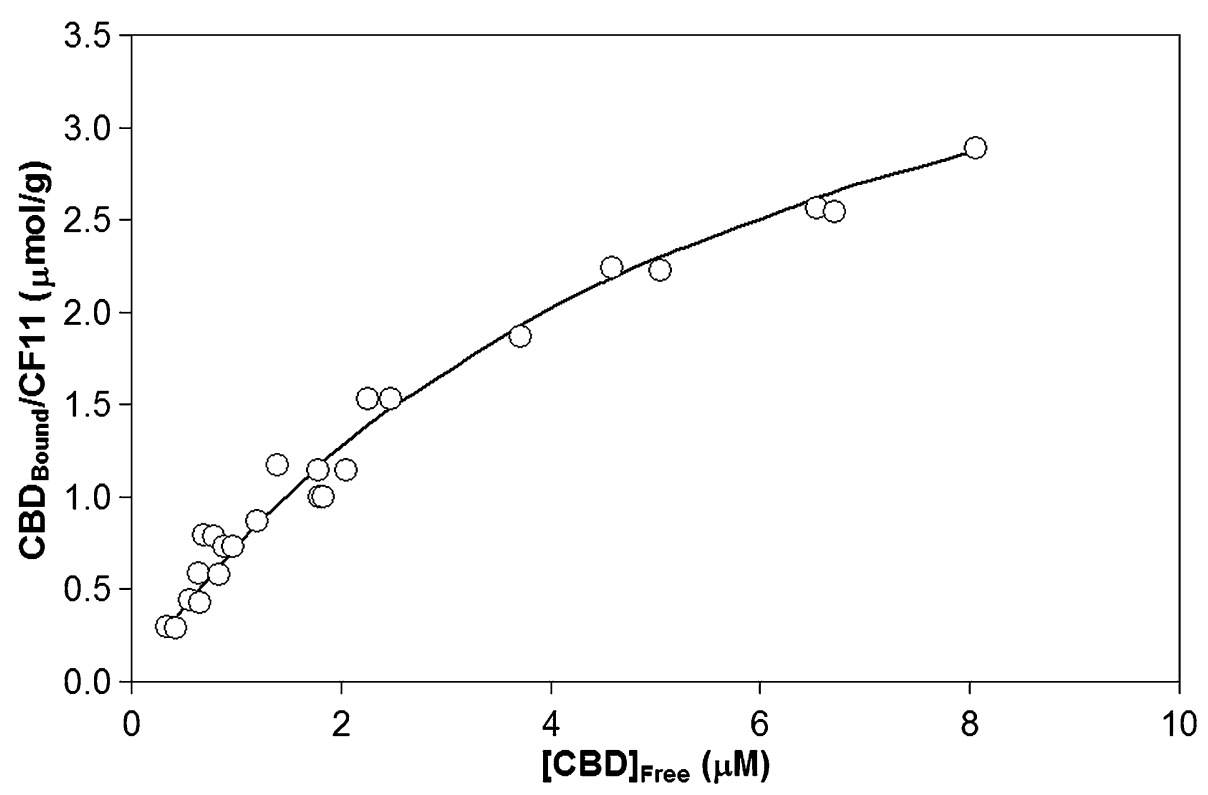

Figure 7. Adsorption isotherm of CBD purified by ion exchange chromatography. 
former were removed by exclusion chromatography, as described in the Methods section. As reported by other authors (Hildén et al. 2003), we verified that the presence of the free fluorescent probe on the surface of cellulose fibers was not detected under the conditions of the experiment. A range of concentrations, from 0 to $300 \mu \mathrm{g} / \mathrm{ml}$ of labeled CBDs, was used in the treatment of different cellulose fibers: Avicel and Whatman CF11. As may be seen in Figure 8 (left column), no fluorescent emission was detected in the control (non-treated) fibers. As the concentration of FITC-labeled CBD increases (50, 100 and $300 \mu \mathrm{g} /$ $\mathrm{ml}$ ) and, consequently, the amount of adsorbed labeled peptides (a minimum of $79 \%$ adsorption was recorded), the fluorescence emission increases as well. It appears that this approach allows - at the very least - a qualitative characterization of the relative concentration of adsorbed CBDs. However, it has been possible to quantitatively estimate the amount of adsorbed protein (to be shown elsewhere). Attention should be brought to the fact that the distribution of CBDs on the fibers is not uniform but concentrated around the fiber extremities.

In another experiment, our objective was to check whether the CBD adsorption is a reversible process. Cellulose fibers previously treated with labeled CBD were mixed in fresh buffer with untreated fibers. This mixture of fibers was kept in suspension with orbital stirring, and samples were collected for microscopic observation at various time points. The goal of this experiment was to evaluate whether the CBD would transfer among fibers. Figure 9 clearly shows that initially $(0 \mathrm{~h}$, top row) both fluorescent and non-fluorescent fibers are detectable based on a comparison of the images obtained with bright field or fluorescent microscopy: only those fibers pretreated with CBD-FITC are visible when both the fluorescent and bright field were used, while the untreated fibers are visible only when the bright field was used. As the time of contact in aqueous suspension of untreated and CBD-FITC-treated fibers increases from 2 to $192 \mathrm{~h}$, all of the fibers become fluorescent. However, a uniform distribution of CBDs is not observed even after a long time of contact (approx. $192 \mathrm{~h}$ ), a result that would be expected if the CBD were perfectly reversibly adsorbed. Pinto et al. (2004) demonstrated that the dilution of fibers with adsorbed CBD (in equilibrium with soluble peptides) did not lead to an increase in the concentration of unbound CBDs, leading to the conclusion that CBD were irreversibly adsorbed. The results of the present experiment demonstrate that, in fact, CBD are not totally irreversibly adsorbed and that, in fact, desorption may be a rather slow process. For instance, after $24 \mathrm{~h}$ of incubation some fibers, observed with bright field microscopy, were still not detectable when a filter for select fluorescent emission was used. Several experiments were conducted, and the images shown in Figure 9 represent the general trend observed: labeled CBD
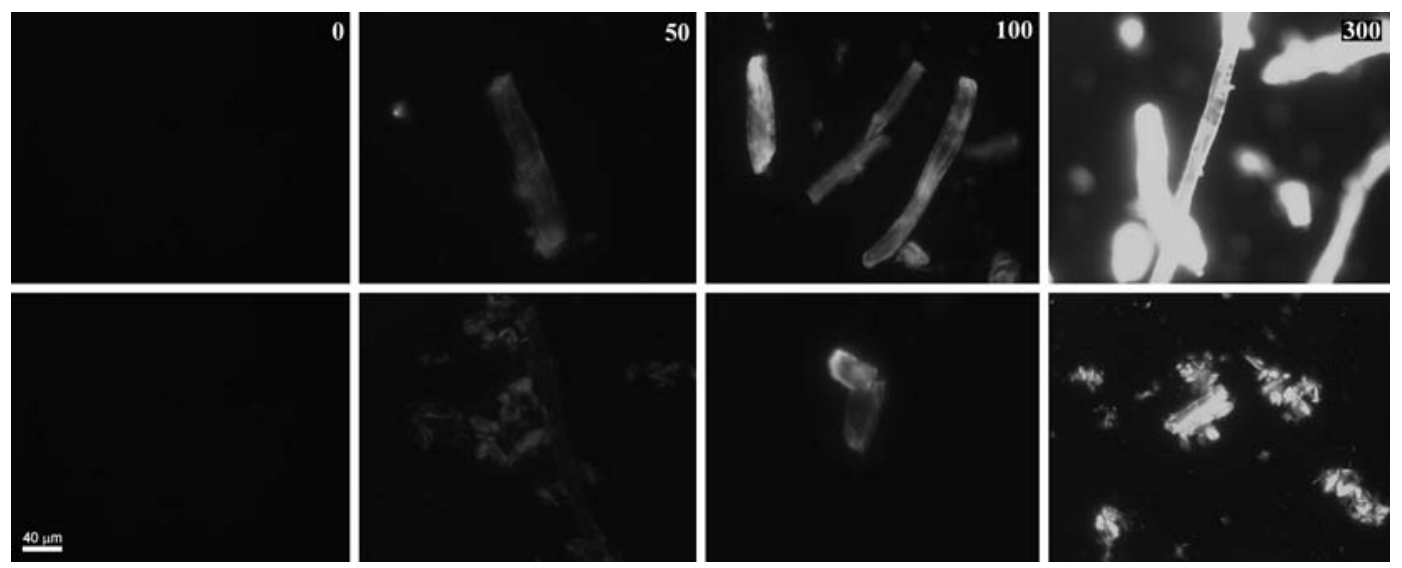

Figure 8. Fluorescence microscopy of Whatman CF11 (upper row) and Avicel (lower row) cellulose fibers treated with labeled CBD at different initial concentrations $(0,50,100$ and $300 \mu \mathrm{g} / \mathrm{ml})$. In the control fibers (left column), as expected, no fluorescence was detected. The micrographs were obtained using the same exposure time. 

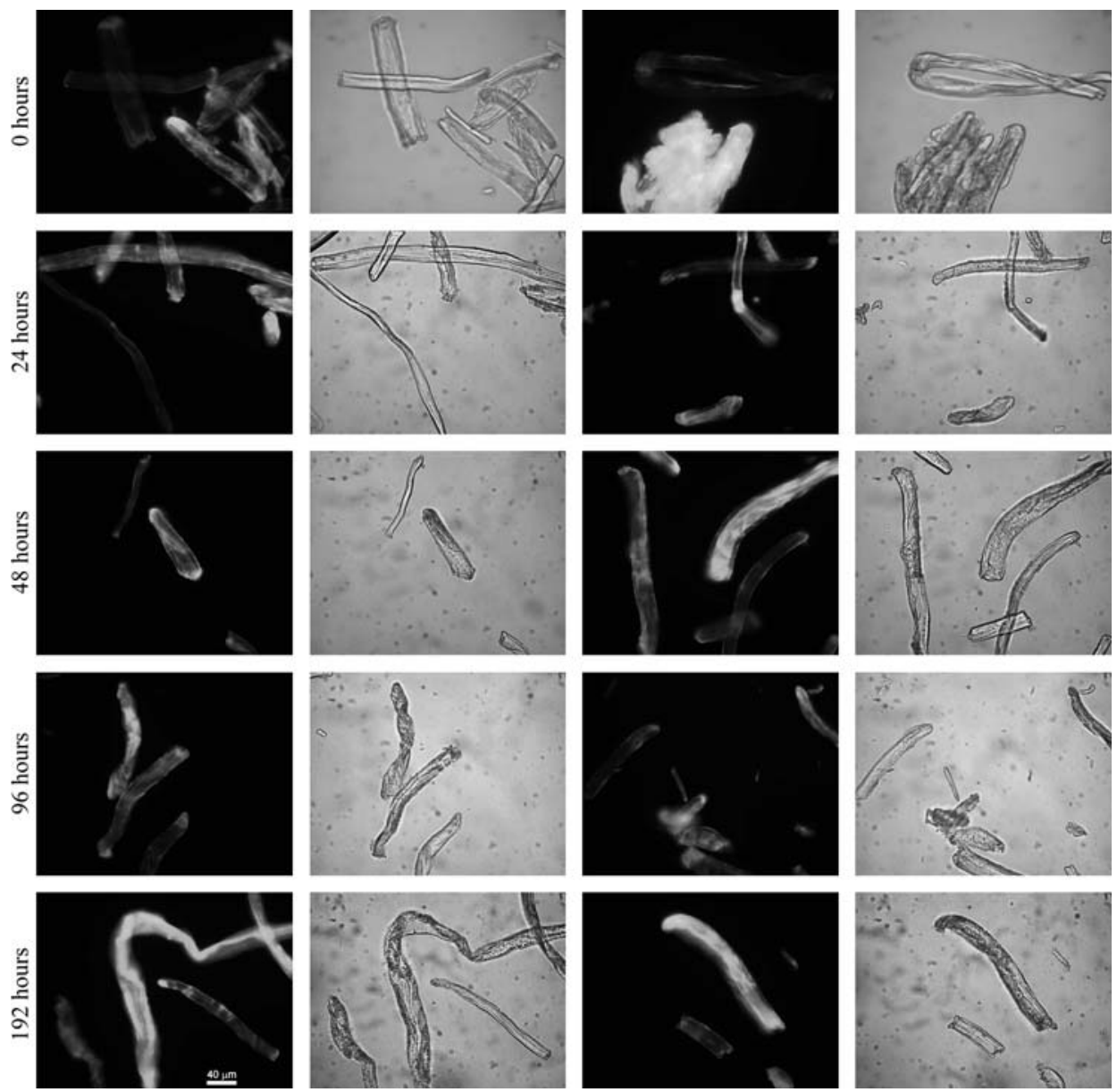

Figure 9. Images of a mixture of treated and untreated CF11 cellulose fibers with labeled CBD under fluorescent (first and third columns) and bright field (second and fourth columns) microscopy, with $400 \mathrm{~ms}$ of exposure time and contact times of $0,24,48,98$ and $192 \mathrm{~h}$.

transfer, very slowly, from fiber to fiber. The results shown in Figure 9 represent a consistent general trend, as revealed by microscopic observation of the fibers. An alternative approach to studying the transfer of CBD among fibers was considered: the analysis of the fluorescence exhibited by one specific fiber and its variation during the time of incubation, with checking the release (desorption) of adsorbed CBD. However, this was judged not to be a feasible approach since the specific fluorescence of the fibers is modified upon repeated observation.

Whatman CF11 is essentially a crystalline cellulose (Pinto et al. 2004), but a few amorphous spots - for example, a fiber's terminations and middle twisted regions - are also present in celluloses purified from wood (Teeri 1997). A disordered packing of the microfibrils characterize these regions (non-uniformity), resulting in a higher surface area available for CBD adsorption. This would explain why the extremities and some middle regions of the crystalline fibers present a brighter fluorescence (Figure 10, top pictures) and may be due either to a higher peptide affinity or to a higher concentration of adsorbing sites at the surface of the fibers (Hildén et al. 2003). Other authors (Linder et al. 1996; Bothwell et al. 1997) have shown that CBD have a differential affinity for celluloses with different crystalline properties and/or surface areas. It is therefore likely that the non-uniform surface distribution of CBD may reveal this differential affinity (which may depend 

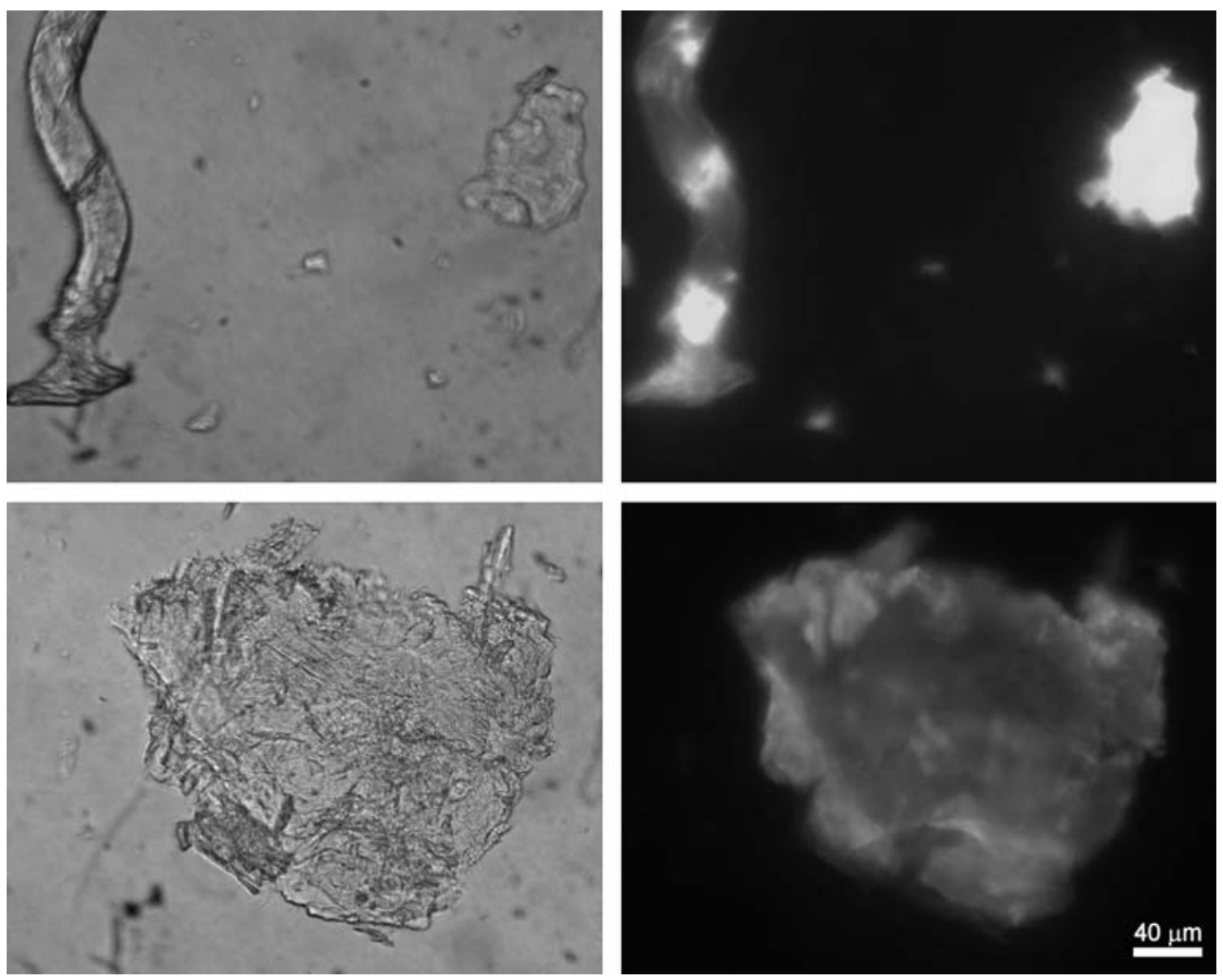

Figure 10. Comparison of the crystalline (top row) and phosphoric acid-swollen (amorphous, bottom row) Whatman CF11 fibers, both treated with FITC-labeled CBD, under bright field (left) and fluorescent (right) microscopy. The probably amorphous sites of the microfibril (left side of the upper images) have attracted more FITC-labeled CBD.

on different degrees of cellulose organization, hydrophilicity, irregularity, etc.). The mode of action of the CBHI enzyme can also explain this behavior since it acts from the loose ends of microfibrils (Teeri 1997). Therefore, it seems likely that $\mathrm{CBD}_{\mathrm{CBHI}}$ would adsorb preferentially at the microfibril's loose ends (mainly in amorphous regions). These results indicate that the labeled CBD may be used to identify, and possibly quantify, the amorphous regions/fibers of cellulose products.

\section{Conclusions}

Applying the CBD production method presented herein, it is possible to obtain grams of protein in a relatively fast way. The CBD obtained are almost pure and identified as belonging to Trichoderma reesei's cellobiohydrolase I family based on the $\mathrm{N}$ terminal sequencing, MALDI analysis and the fluorescence spectrum. The purified protein comprises the $\mathrm{CBD}$ with the attached glycosylated linker. In a forthcoming work, the effect of oligosaccharides on the CBD properties will be analyzed. Microscopic observation of fibers treated with FITC-labeled CBDs revealed that these have a higher affinity towards amorphous cellulose. It was also shown that $\mathrm{CBD}$ adsorption is partially reversible, although desorption occurs at a very low rate. FITC-labeled CBD may be used in techniques designed to rapidly detect - by visual means - the degree of crystallinity of celluloses from different sources.

\section{Acknowledgements}

We wish to acknowledge Ana Varela Coelho for providing the MALDI-TOF data and Maria Manuela Regalla for the N-terminal sequencing analysis, both at the Instituto de Tecnologia 
Química e Biológica, Universidade Nova de Lisboa, Oeiras, Portugal. Ricardo Pinto was supported by Fundação para a Ciência e a Tecnologia (FCT) grant SFRH/BD/6934/2001. The authors are grateful to funding from EU and FCT, respectively, through the projects GLK3/CT/2000/ 273 and POCTI AGR/38253/2009.

\section{References}

Blakeney A.B., Harris P.J., Henry R.J. and Stone B.A. 1983. A simple and rapid preparation of alditol acetates for monosaccharide analysis. Carbohydr. Res. 113: 291-299.

Bothwell M.K., Daughhetee S.D., Chaua G.Y., Wilson D.B. and Walker L.P. 1997. Binding capacities for Thermomonospora fusca E3, E4 and E5, the E3 binding domain, and Thichoderma reesei $\mathrm{CBHI}$ on avicel and bacterial microcrystalline cellulose. Bioresource Technol. 60: 169-178.

Carrard G. and Linder M. 1999. Widely different off rates of two closely related cellulose-binding domains from Trichoderma reesei. Eur. J. Biochem. 262: 637-643.

Carrard G., Koivula A., Söderlund H. and Béguin P. 2000. Cellulose-binding domains promote hydrolysis of different sites on crystalline cellulose. Proc. Natl. Acad. Sci. USA 97: $10342-10347$.

Creagh A., Ong E., Jervis E., Kilburn D. and Haynes C. 1996. Binding of the cellulose-binding domain of exoglucanase Cex from Cellulomonas fimi to insoluble microcrystalline cellulose is entropically driven. Proc. Natl. Acad. Sci. USA 93: 1222912234.

Dubois M., Gilles K.A., Hamilton J.K., Rebers P.A. and Smith F. 1956. Colorimetric method for determination of sugars and related substances. Anal. Chem. 28: 350-356.

Edge A.S.B., Connie R.F., Hof L., Reichert L.E. and Weber P. 1981. Deglycosylation of glycoproteins by trifluoromethanesulfonic acid. Anal. Biochem. 118: 131-137.

Gao P.-J., Chen G.-J., Wang T.-H., Zhang Y.-S. and Liu J. 2001. Non-hydrolytic disruption of crystalline structure of cellulose by cellulose binding domain and linker sequence of cellobiohydrolase I from Penicillium janthinellum. Acta. Biochim. Biophys. Sin. 33: 13-18.

Gasteiger E., Gattiker A., Hoogland C., Ivanyi I., Appel R.D. and Bairoch A. 2003. ExPASy: the proteomics server for indepth protein knowledge and analysis. Nucleic Acids Res. 31: 3784-3788.

Harris P.J., Blakeney A.B., Henry R.J. and Stone B.A. 1988. Gas chromatographic determination of the monosaccharide composition of plant cell wall preparations. J. Assoc. Off. Anal. Chem. 71: 272-275.

Harrison M.J., Nouwens A.S., Jardine D.R., Zachara N.E., Gooley A.A., Nevalainen H. and Packer N.H. 1998. Modified glycosylation of cellobiohydrolase I from a high cellulase-producing mutant strain of Trichoderma reesei. Eur. J. Biochem. 256: 119-127.

Harrison M.J., Wathugala I.M., Tenkanen M., Packer N.H. and Nevalainen K.M.H. 2002. Glycosylation of acetylxylan esterase from Trichoderma reesei. Glycobiology 12: 291-298.
Hildén L., Daniel G. and Johansson G. 2003. Use of a fluorescence labelled, carbohydrate-binding module from Phanerochaete chrysosporium Cel7D for studying wood cell wall ultrastructure. Biotechnol. Lett. 25: 553-558.

Hui J.P.M., Lanthier P., White T.C., McHugh S.G., Yaguchi M., Roy R. and Thibault P. 2001. Characterization of cellobiohydrolase I (Cel7A) glycoforms from extracts of Trichoderma reesei using capillary isoelectric focusing and electrospray mass spectrometry. J. Chromatogr. B 752: 349 368.

Kim D.W., Jang Y.H., Kim C.S. and Lee N.-S. 2001. Effect of metal ions on the degradation and adsorption of two cellobiohydrolases on microcrystalline cellulose. Bull. Korean Chem. Soc. 22: 716-720.

Kraulis P.J., Clare G.M., Nilges M., Jones T.A., Pettersson G., Knowles J. and Gronenborn A.M. 1989. Determination of the three-dimensional solution structure of the C-terminal domain of cellobiohydrolase I from Trichoderma reesei. A study using nuclear magnetic resonance and hybrid distance geometry-dynamical simulated annealing. Biochemistry 28 : $7241-7257$.

Leach B.S., Collawn J.F. and Fish W.W. 1980. Behavior of glycopeptides with empirical molecular weight estimation methods. Biochemistry 19: 5734-5741.

Legaz M.E., Pedrosa M.M., Armas R., Rodríguez C.W., Rios V. and Vicente C. 1998. Separation of soluble glycoproteins from sugarcane juice by capillary electrophoresis. Anal. Chim. Acta 372: $201-208$.

Lemos M.A., Teixeira J.A., Mota M. and Gama F.M. 2000. A simple method to separate cellulose-binding domains of fungal cellulases after digestion by a protease. Biotechnol. Lett. 22: 703-707.

Letourneur O., Gervasi G., Gaia S., Pages J., Watelet B. and Jolivet M. 2001. Characterization of Toxoplasma gondii surface antigen 1 (SAG1) secreted from Pichia pastoris: evidence of hyper O-glycosylation. Biotechnol. Appl. Biochem. 33: $35-45$.

Levy I., Shani Z. and Shoseyov O. 2002. Modification of polysaccharides and plant cell wall by endo-1,4- $\beta$-glucanase and cellulose-binding domains. Biomol. Eng. 19: 17-30.

Linder M., Salovuori I., Ruohonen L. and Teeri T.T. 1996. Characterization of a double cellulose-binding domain. Synergistic high affinity binding to crystalline cellulose. J. Biol. Chem. 271: 21268-21272.

Linder I., Nevanen T. and Teeri T.T. 1999. Design of a pHdependent cellulose-binding domain. FEBS Lett. 447: 13-16.

Mattinen M.-L., Linder M., Teleman A. and Annila A. 1997. Interaction between cellohexaose and cellulose binding domains from Trichoderma reesei cellulases. FEBS Lett. 407: 291-296.

Pala H., Lemos M.A., Mota M. and Gama F.M. 2001. Enzymatic upgrade of old paperboard containers. Enzyme Microb. Technol. 29: 274-279.

Pinto R., Moreira S., Mota M. and Gama M. 2004. Studies on the cellulose-binding domains adsorption to cellulose. Langmuir 20: 1409-1413.

Price N.C. and Johnson C.M. 1990. Proteinases as probes of conformation of soluble proteins. In: Beynon R.J. and Bond J.S (eds), Proteolytic enzymes: a practical approach, IRL Press, Oxford, pp. 163-180. 
Selvendran R.R., March J.F. and Ring S.G. 1979. Determination of aldoses and uronic acid content of vegetable fiber. Anal. Biochem. 96: 282-292.

Srisodsuk M., Reinikainen T., Pentillä M. and Teeri T.T. 1993. Role of the interdomain linker peptide of Trichoderma reesei cellobiohydrolase I in its interaction with crystalline cellulose. J. Biol. Chem. 266: 20756-20761.

Srisodsuk M. 1994. Mode of action of Trichoderma reesei cellobiohydrolase I on crystalline cellulose. Ph.D. thesis, Technical Research Centre of Finland (VTT), Helsinki, Finland.

Suurnakki A., Tenkanen M., Siika-aho M., Niku-Paavola M.-L., Viikari L. and Buchert J. 2000. Trichoderma reesei cellulases and their core domains in the hydrolysis and modification of chemical pulp. Cellulose 7: 189-209.
Tilbeurgh H.V., Tomme P., Claeyssens M., Bhikhabhai R. and Pettersson G. 1986. Limited proteolysis of the cellobiohydrolas I from Trichoderma reesei. Separation of functional domains. FEBS Lett. 204: 223-227.

Teeri T.T. 1997. Crystalline cellulose degradation: new insight into the function of cellobiohydrolases. Trends Biotechnol. 15: $160-167$.

Xiao Z., Gao P., Qu Y. and Wang T. 2001. Cellulose-binding domain of endoglucanase III from Trichoderma reesei disrupting the structure of cellulose. Biotechnol. Lett. 23: $711-715$. 